\title{
Power Factor Improvement Using Automatic Power Factor Compensation (APFC) Device for Medical Industries in
}

\section{Malaysia}

\author{
Maryam Nabihah Zaidi ${ }^{1, *}$, Adlan Ali $^{1}$ \\ ${ }^{1}$ Department of Electrical Engineering Technology, Universiti Teknikal Malaysia Melaka, Melaka, Malaysia
}

\begin{abstract}
This paper present the project designed to correcting power factor for medical industries in Malaysia automatically. Which with hope to make the cost and energy usage efficient, because the energy source are depleting due to increase in population. Power factor is the ratio of real power and apparent power. This definition is mathematically represented as $\mathrm{kW} / \mathrm{kVA}$ where $\mathrm{kW}$ is active power and $\mathrm{kVA}$ is apparent power (active + reactive). Reactive power is the non-working power generated by the magnetic and inductive load to generate magnetic flux. The increase in reactive power increase the apparent power so the power factor will decrease. Low $\mathrm{pF}$ will cause the industry to meet high demand thus making it less efficient. The main aim of this project is to increasing the current power factor of medical industries from 0.85 to 0.90 . Power factor compensation contribute to reduction in current-dependent losses and increase energy efficiency while expanding the reliability of planning for future energy network. As technology develops, the gradual cost and efficiency penalty should reduce. Therefore, automatic power factor compensation device should become cost-effective and smaller device over time. That is the reason this project is using programmable device as it is a miniature architecture device.
\end{abstract}

\section{Introduction}

Electrical power has been proven to be one of the most important resource in Malaysia and due to its high demand and widely used, it has become a very expensive resource. The cause of its high cost is mainly because of the generation cost, transmission cost and distribution cost. Plus, the demand of commercial and industrial customers varies greatly throughout the day and for them (the industrial consumers) the maximum demand plays an important role in their overall electricity bills. Therefore, they need to ensure that their max demand is low as possible for their substantial savings. This is the main purpose of this project where it is to overcome the unwanted problem, power factor need to be improved by installing Automatic Power Factor Compensation (by adding capacitor load to offset the inductive load present in the power system). The capacitors can be installed at the service entrance of the plant or on the load side of the metering equipment. These capacitors may supply part, or all of the reactive power required by the plant. There are many benefits by having Automatic Power Factor Compensation device. For the industrial usage, the equipment will have a longer life span and the maintenance costs remain low. According to Sandesh, Singh and Phulambrikar (2012), power factor improvement leads to a huge drop of apparent power drawn from the ac source which in turn protects energy and minimizes the transmission losses.

This project will make the consumers actually see the effect of high and low power system in their consumption of energy. When the power factor is very low, the may be able to see the effect and reach out to make the operation system change as needed. They can increase the power factor by using the automatic power factor compensation which use capacitor and microcontroller as the main components. Thus, this will help in improving the power factor of a system. Plus, the current demand on energy is increasing day by day and the industries growth are inclining. Plus, according to Ministry of Health Malaysia $(\mathrm{MoH})$, medical industries had been tremendously grow for the past decades, $8 \%$ to $10 \%$ annually. But on the other hand, the energy sources are depleting due to increase in population.

\subsection{Power Factor}

Ware, J. (2006) described that power factor is the ratio between the useful (true) power (kW) to the total (apparent) power (kVA) consumed by an item of alternating current (A.C) electrical equipment or a complete electrical installation. It is a measure of how efficiently electrical power is converted into useful work output. The ideal power factor is unity, or one. Anything less than one means that extra power is required to achieve the actual task at hand. Power factor is expressed as a percentage $(\%)$.

$$
\text { Power factor }=\frac{\text { Real power }(k W)}{\text { Total power }(k V A)} \times 100
$$

Real power or true power, $\mathrm{P}$ is the power that is used to do work on the load. Active power is measured in watts $(W)$ and in the electricity billing, it is stately in kilowatthours $(\mathrm{kWH})$. It is the power drawn by the electrical

* Corresponding author: zmaryamnabihah@yahoo.com 
resistance of a system doing useful work. Reactive power is the power not used to do work on the load.

Kanchi et al. (2013) have described that generally, power factor is called as the cosine of angle between the voltage and current. In an a.c circuits there is generally a phase difference between voltage and current. If the circuit is inductive, the current is lags behind the voltage and the power factor is called lagging power factor and if the circuit is capacitive then current leads to voltage and power factor is said to be leading power factor.

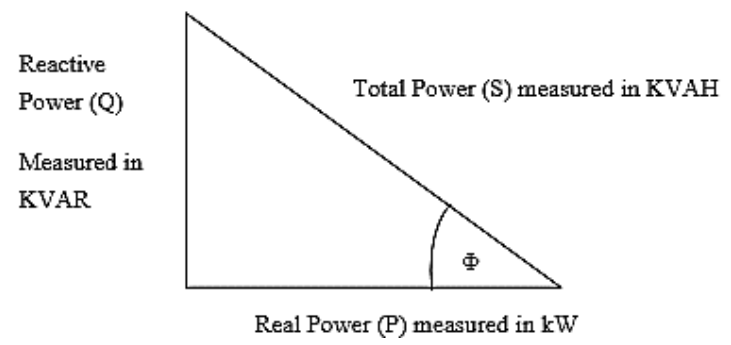

Fig. 1. Power triangle (source: Tagwira, 2014)

The power factor of an alternating-current device or circuit is the ratio of the active power $\mathrm{P}$ to the apparent power S. Power factor is expressed as a simple number, or as a percentage. It is given by the equation;

$$
\text { Power factor }=P / S
$$

where; $\mathrm{P}=$ active power delivered or absorbed by the circuit or device [W]

$\mathrm{S}=$ apparent power of the circuit or device [VA]

The power factor never exceed 100 percent or unity because the value of active power can never be greater than apparent power. Power factor is also a measure of the phase angle between voltage and current. Where this leads to another equation,

$$
\begin{aligned}
\text { Power factor } & =\frac{P}{S} \\
& =\frac{E I_{p}}{E I} \\
& =I_{p} / I \\
& =\cos \theta
\end{aligned}
$$

Neha Shrivastava (2015) stated that the AC circuits are made of resistive, inductive and capacitive components. For purely resistive load like incandescent lighting, the current and voltage are in phase where the current follows the voltage. For inductive loads case, the current is out of phase with voltage where it lags behind the voltage except for a few purely resistive loads and synchronous. However, in a capacitive load the current leads the voltage thus means the current and voltage are out of phase. The most common capacitive loads are the capacitors used for the correction of power factor of the load.

\section{Power Factor Correction}

Power factor correction can be applied by the electrical utility to improve the stability and efficiency of the transmission network or, it can be installed by the electrical consumer to reduce costs charged by the electrical provider.

Wildi, T. (2006) mentioned that power factor correction (or improvement) is economically practicable whenever the decrease in the annual cost of electricity exceed the pay back cost of installing the required capacitors. In some cases, the customer has no choice but must obey with the minimum power factor specified by the utility company. The power factor may be amended by installing capacitors at the commercial enterprise or at the service entrance of the factory. In other cases, if the power factor is particularly low, it may be necessary to correct the power factor of the device or machine individually.

Power factor compensation can be defined as a process of correcting the lagging current by producing leading current so that the angle between voltage and current reduces. There will be no power loss if the current and voltage are in phase, thus it can improve the power factor value to nearly unity or even unity. The process is done by connecting few capacitors at the service entrance where the power factor is attuned by an adequate value of capacitance.

The electrical loads that work on alternating current need apparent power which is the product of real power and reactive power. The reason why the electrical load has power factor less than one is, the existence of reactive power makes the apparent power higher than real power. The reactive power increases the current flow from the power sources and the load. When this happens, power losses increases in both distribution and transmission lines. Thus, this results in financial losses for the power provider like Tenaga Nasional Berhad (TNB) which made them require their consumers and customers, especially those who use large loads to maintain their power factor above 0.85 or higher.

Besides the increased in operation costs, reactive power requires the use of higher current capacitance components like wires, switches, transformer and circuit breakers. Power factor can be improved by few methods such as installed capacitor banks in parallel, synchronous condenser and phase advancer.

\subsection{Passive power factor compensation}

Passive PFC needs lager inductor than active PFC but it still cost less. This is an easy way to correct the nonlinearity in a load by using capacitor bank but it is not as effective as active PFC.

\subsection{Active power factor compensation}

Active PFC is a power electronic system that modified the wave shape of current drawn by a load to correct the power factor. The reason is to make the power factor corrected appear purely resistive so that the voltage and 
current are in phase and the reactive power consumption is zero. This allows the most efficient distribution of electrical power from the power company to the consumer. There are few types of active PFC which are Boost, Buck and Buck-boost.

\subsection{TNB power factor surcharge}

According to Tenaga Nasional Berhad (TNB), for customers taking supply at $33 \mathrm{kV}$ or below, the value of the power factor to be retained is more or equal to 0.85 . For customers taking supply at $132 \mathrm{kV}$ or above, the value of the power factor to be retained is more or equal to 0.90 . If the consumers cannot oblige the value needed, they will be penalised by the power provider in power factor surcharge. A high Power Factor index (e.g. above 0.85 or 0.90 ) indicates an efficient level of electricity usage. On the other hand, a low Power Factor index (e.g. under 0.85 or 0.90) shows an inefficient use of electricity, indicating electricity wastage.

Plus, according to Ministry of Energy, Green Technology and Water (KeTTHA) regulates the electricity tariffs charged by the utilities to final consumers in Peninsular Malaysia and Sabah in pursuance of the Electricity Supply Act 1990. Among the principles applied in determining tariff rate is:

- The tariff should reflect the cost supply.

- Provide adequate revenue for the development of the power sector.

- Competitiveness among the industries and services.

- Affordability of the consumers and social economic objectives of the government.

TNB imposes on all industrial and low power consumer to maintain their power factor to no less than 0.85 . Failing to maintain the required PF will result on a penalty being imposed on them. The penalty is incorporated into the tariff structure. The consumer should use their best endeavours to obtain highest possible in PF in the operation of any of their electrical installation. Based on TNB, power factor below 0.85 and up to 0.75 $(0.85>P F \geq 0.75)$ lagging, a supplementary charge $1.5 \%$ of the bill for the month for each 0.01 unit below 0.85 and up to 0.75 lagging PF will be added to the bill for that month. On the other hand, power factor below 0.75 lagging, in addition to the charge payable under the above condition, a supplementary charge of $3 \%$ of the bill for that month for each 0.01 unit below 0.75 lagging PF will be added to the bill of the month.

Effectively, on $1^{\text {st }}$ June 2011, the electricity tariff was reviewed. It is structured to balance between protecting low income group and sustaining the nation's competitiveness. Prior to that, the last review was carried out in $1^{\text {st }}$ March 2009. The electricity tariff rate are based on the following guideline:

- The amount of energy consumed (kWh)

- The maximum demand at which energy consumed $(\mathrm{kW})$

- Peak or off peak period

- The power factor of the load
- The connected load

\subsection{The uses of capacitors in APFC}

An automatic power factor correction unit have a number of capacitors that are switched by means of contactors. These contactors are controlled by a regulator that measures power factor in an electrical network or individual motors. This assures that only the needed capacitor is energized depending on the load and power factor of the network to ensure the power factor remains above a selected value. For this type of application, usually a fixed capacitor is used because it is the simplest and cheapest way of power factor correction, based on Tagwira (2014) research.

A capacitive load bank is like a reactive load bank in rating and purpose, except leading power factor loads are created. These loads simulate certain electronic or nonlinear loads typical of telecommunications, computer or UPS industries. An automatic capacitor system should be used for multiple loads in order to reassure a proper value of power factor capacitor is always connected to the system. Therefore, a microcontroller is used to form the automatic power factor compensation.

\subsection{Location for APFC}

Failing to correct the power factor value will make the source carry excess current and collapsing the magnetized field. This can limit the capacity of components in transmission line. Because the capacitor delivers the magnetizing current the cable from the power source only need to supply the load current. The cable and other components where the capacitor links in, supply load current only to the motor. Therefore, they do not need to be sized to handle the magnetizing current of the motor. Load current has been accentuated because the current flow to the load has only been corrected upstream of the point in the system where the capacitor is link in. There is no change to the current flow downstream of the tie-in point, which is still carrying the magnetizing current. Thus, finding the PF correction location is significant in achieving the required power factor.

\subsubsection{PFC at motor}

This way is the most advantageous power factor correction location but it is expensive if it is not prepared at early construction. One good thing about this is that, when the motor is turned off, the capacitor that is not required removes from the circuit.

\subsubsection{PFC at motor control centre}

This can dismiss the equipment upstream of power factor correction location from having to supply the magnetizing current. Which can cause less amperage on the components that carry power to the motor control centre. But, the drawback is the capacitors may deliver too much reactive load when some of the loads are turned off. 


\subsubsection{PFC at utility meter}

This method is to simply cut down the need to pay large reactive demand charges (TNB power factor surcharge) where the capacitor bank is installed at the service entrance. This will profit the utility line because they no longer need to deliver magnetizing current and they have more current carrying capacity to be sold to others.

\subsubsection{PFC at substation transformer}

Placing the power factor compensating device at the substation transformer can help to re-feed the loads from another source. The position of the capacitors need to be on the correct side of the transformer, so it is better to link it on the secondary side. By this way, the equipment upstream of the link in point will be benefited.

\section{Flow of the system}

The automatic power factor compensation device is to collect and analyse the voltage and current in the electrical system to make a correction in the power factor. Firstly, the two interrupt pins of the microcontroller are provide with time lag between the zero voltage pulse and zero current pulse duly created by suitable operational amplifier circuits in comparator mode. It shows the time lag between the current and voltage on an LCD. The program takes over to actuate suitable number of relays from its output to bring shunt capacitors into the load circuit to get the power factor till it reaches near unity. The microcontroller used in the project belongs to 16PF877A. The construction of the automatic power factor correction circuit are as shown in Figure 2.

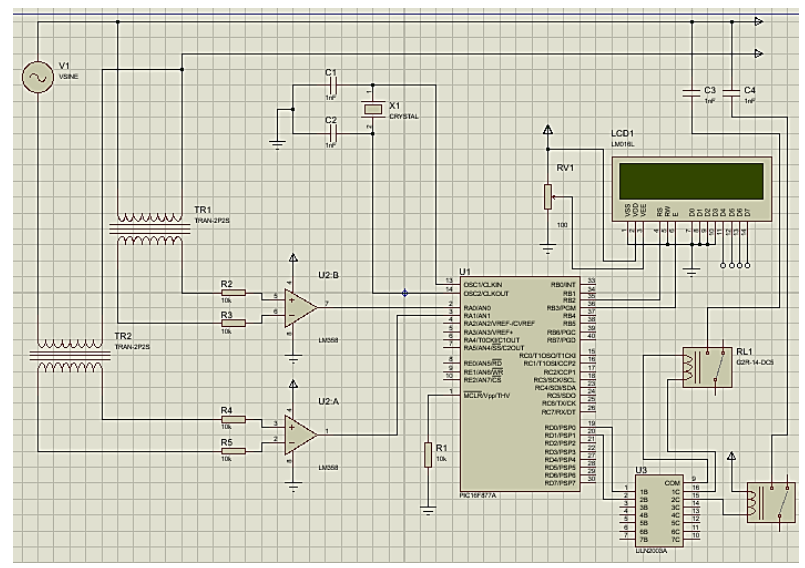

Fig. 2. Automatic Power Factor Correction circuit

This project consist of five main circuit which can be explained in simple block diagram. Those circuits are:

i. Voltage sensing circuit

ii. Current sensing circuit

iii. Data calculation circuit

iv. Display circuit

v. Power factor correcting circuit

\subsection{Voltage sensing}

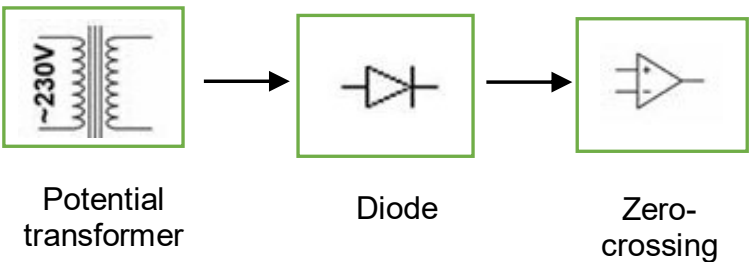

Fig. 3. Block diagram of voltage sensing

The transformer used for this project is a step-down transformer. The potential transformer is fed with alternating voltage with a value of $220 \mathrm{~V}$ and the value is step down to less than $5 \mathrm{~V}$. The output of the transformer is connected to diode. The diode act as rectifier which converted the voltage wave into pulsating D.C. wave to be detected by the microcontroller. The output of the diode is then connected to the zero-crossing detector where zero crossing detection is used to sense sine wave zero crossing from positive half cycle to negative half cycle or vice-versa

\subsection{Current sensing}

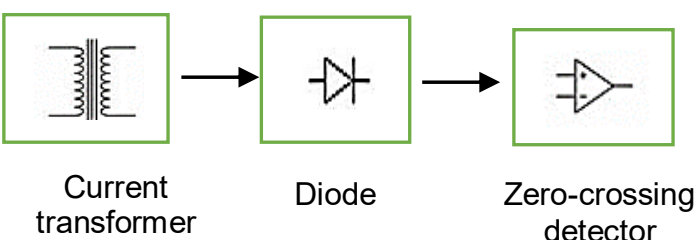

Fig. 4. Block diagram of current sensing

The current sensing circuit works the same as voltage sensing circuit but this circuit detects current. The input signal is connected to the step down current transformer where it converts high current in to low current output for the use of different electrical circuits. The reason current transformer is used because, Op-amp requires current less than 50mA. Output of current transformer is connected to diode. Diode function as a rectifier in the circuit and it is connected to zero-crossing detector. This zero-crossing detector detects sine wave zero crossing.

\subsection{Data calculation circuit}

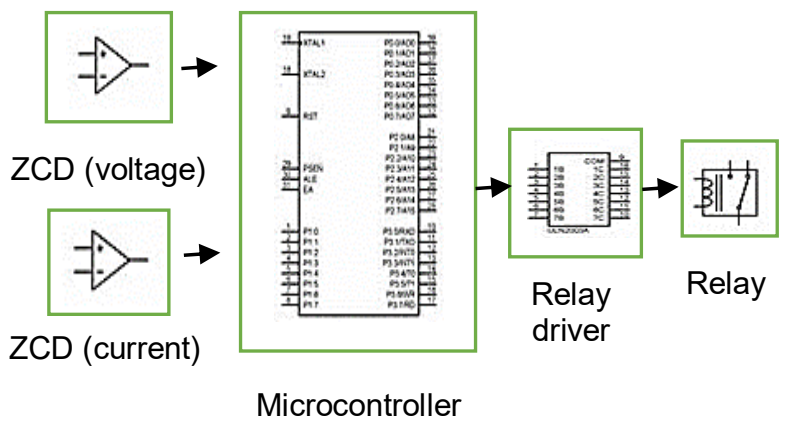

Fig. 5. Block diagram of data calculation process 
The data calculation process is the most important circuit on this project. Zero crossing detector converts sinusoidal wave to square wave and it uses op-amp as the comparator. When the sinusoidal signal has value greater than 0 reference, op-amp output has positive value. But, output of op-amp drop to 0 when the sinusoidal signal drops below 0 . This way, the zero crossing detector can convert sinusoidal signal to square signal or PWM. The op-amp proposed to be used is the LM385 because it can operate at a very low voltage $(3 \mathrm{~V})$ and very high voltage $(32 \mathrm{~V})$. The output from the zero crossing detectors are now fed to the pins of PIC of microcontroller and the data collected are send to the microcontroller. Then, microcontroller uses its capabilities and program to calculate the phase angle and phase difference between two waveforms.

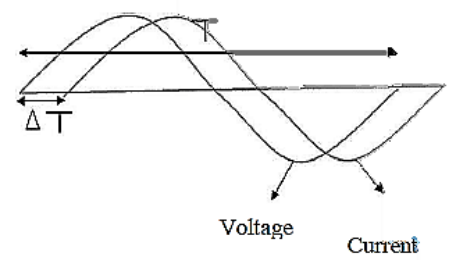

Fig. 6: Voltage and Current wave with time difference

\subsection{Result display}

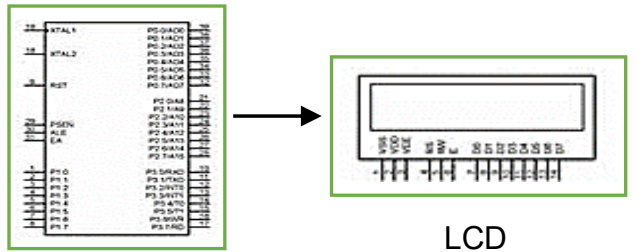

Microcontroller

Fig. 7. Block diagram of result display

The pins of microcontroller are connected to the LCD pins. Once the microcontroller program calculates the phase difference between two sinusoid waves and power factor, the information is then displayed on the LCD screen. Liquid Crystal Display screen is very simple module and is used very frequently in various circuits for display purpose. It has a wide range of applications.

\subsection{Power factor correcting}

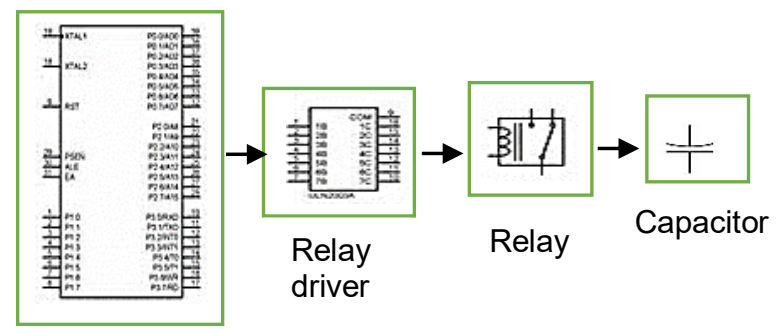

\section{Microcontroller}

Fig. 8. Block diagram of power factor correcting process
If the power factor is less than the approved value then microcontroller produce command to turn on the relay. Turning on relay will add capacitor into the circuit which can help to improve power factor. Capacitors add reactive load in the circuit which will help to increase power factor. Number of capacitors need to be added depends on the power factor of the circuit. As soon as the power factor drops from a specific value, the relay will add capacitor to the circuit. If power factor's value drops a little from the wanted value then one capacitor is added. In case of power factor falls more than prescribed value then second capacitor is added and the system will keep on working this way. The circuit will continue to add capacitor in parallel to the load until a good value of power factor is attained.

\section{Effectiveness and Efficiency}

The main purpose of automatic power factor compensation is to help correcting the excess reactive power generate by inductive loads in the industry. With an efficient use of this device, the industry can improves efficiency of the system by reducing losses and reduced apparent power demand charges. Thus, eliminates low power factor penalties levied by TNB. The aim power factor proposed is 0.90 which is convincing as it gives the power factor compensation system a sufficient control capability.

According to European Community, 94\% of reactive power demand comes from sectors of industry and services and when they maintained their power factor to 0.95 , the sum of active energy and reactive energy falls from 3173TVAh (without power factor compensation) to $2730 \mathrm{TVAh}$. That is $15 \%$ drops and leads to reduction in network losses and reduces the loads on the network. For instance;

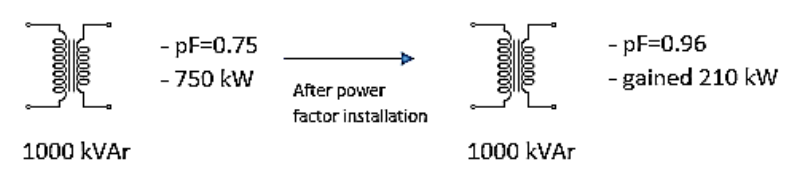

Fig. 9. Effect of installing power factor compensation device on transformer

Based on Fig. 9, after installing the power factor device, the transformer gained $210 \mathrm{~kW}$ which is $28 \%$ from the initial value. This device can limit energy losses in the cable by the Joule effect (limit voltage drop) given the reduction in the current carried in the installation.

According to Ecos, an electronic device with a power factor of 0.40 draws 2.5 times the current compared to an ideal load with a power factor of 1.00. By installing power factor compensation device, it can reduce building wiring losses up to 6.25 times less than the ideal case. 


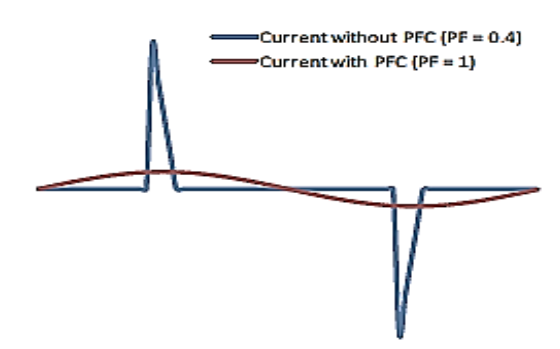

Current draw over one $60 \mathrm{~Hz}$ cycle for a $100 \mathrm{~W}$ device with and vithout $P F C$.

Fig. 10. Effect of installing power factor compensation device on current wave

One of the manufacturer for power factor correction panel in France, Alpes Technologies stated that when the power factor of the industry had been corrected to certain values, it will provide an additional power for the transformer. For example, if the power factor value is corrected to 0.8 , it can give up to $7 \%$ more power to the transformer. And if the power factor value reached the ideal value, 1.0, the additional power to the transformer is around $33 \%$. But the contrast of the current device is, the size is too big and the cost for installing those device is a bit expensive. While, the automatic power factor compensation that been proposed is a miniature architecture device by using a programmable integrated circuit which can cut the cost and space.

M.N. Zaidi and A.Ali gratefully thanks to Universiti Teknikal Malaysia Melaka (UTeM) for providing support for this paper via special funding Paper ID 1570380395. The authors would also want to express their thank you to all parties involved for their effortless support towards the completion of this paper.

\section{References}

1. Babu, I. S., Raju, P.V.R.K.B.A.N., Rao, G. V. S. K., International Journal of Science, Engineering and Technology Research (IJSETR). Simulation of Active Power Factor Correction Using Boost Type Converter, 3 (10), pp. 2755-2759, (2014)

2. Kumar, P., Sharma, P. R., Kumar, A., European Scientific Journal. Simulation \& Design Of Power Factor Correction Prototype For Bldc Motor Control, 9 (12), pp. 141-153, (2013)

3. Mishra, A., Khan, U., Kazi, F., International Journal for Scientific Research and Development. Power Factor Compensation (Reducing Electricity Bill), 3 (12), pp. 845-849, (2016)

4. Nazarkar, S., Shelar, S., International Journal Of Innovations In Engineering Research and Technology. Design \& Simulation Of Active Power Factor, 3 (3), pp. 1-8, (2016)

5. Sullivan, K. R. (no date). Understanding relays, pp. $1-20$.

6. Tade, P. U., Garat, S., Pathilkede, D., Patil, S., Yadav, S., Automatic Power Factor Correction using PIC, (2017)

7. Tagwira, M. P., Design Of An Automatic Power Factor Correction System, (2014)

8. R. Saidur, M. Hasanuzzaman, S. Yogeswaran, H.A. Mohammedc, M.S. Hossain., An End-use Energy Analysis in a Malaysian Public Hospital, (2010)

9. FRAKO, Improving Energy Efficiency by Power Factor Correction, (2008)

10. Ecos, Power Factor Correction: An Energy Effieciency Perspective, (2011) 